\title{
Peripapillary Choroidal Neovascularization Associated with Optic Nerve Head Drusen Treated with Anti-VEGF Agents
}

\author{
Norman A. Saffra ${ }^{a, b} \quad$ Benjamin J. Reinherz ${ }^{b}$

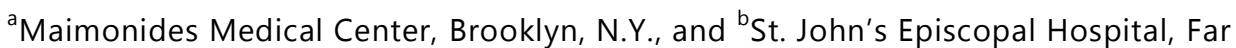 \\ Rockaway, N.Y., USA
}

\section{Key Words}

Peripapillary choroidal neovascularization · Aflibercept · Intravitreal anti-VEGF agents · Optic nerve head drusen

\begin{abstract}
Optic nerve head drusen can be associated with peripapillary choroidal neovascularization, in both the pediatric and adult population. These membranes can involve the macula, causing significant visual loss. Herein, we present a case that required treatment with an anti-VEGF agent. The patient failed to respond to the initial agent, but subsequently responded to a change of agent. Adult patients with macular degeneration involving peripapillary choroidal neovascularization associated with optic nerve head drusen may require individualized treatment plans.

(C) 2015 S. Karger AG, Basel
\end{abstract}

\section{Introduction}

Subfoveal choroidal neovascularization (CNV) is a leading cause of visual loss in the geriatric population [1]. Ten percent of extrafoveal CNV cases occur in the peripapillary region [2]. Peripapillary CNV membranes (PPCNVM) have been associated with multiple etiologies $[2,3]$. While PPCNVM, associated with optic nerve head drusen (ONHD), is a well-described entity in the pediatric population [4], it is not reported in the adult population (PubMed search November 29, 2014). Herein, we report a case of PPCNVM associated with ONHD impacting the macula, which required treatment with an anti-vascular endothelial growth

KARGER 125/s $\quad \begin{aligned} & \text { Norman A. Saffra, MD } \\ & \text { Maimonides Medical Center } \\ & 902 \text { 49th Street } \\ & \text { Brooklyn, NY } 11219 \text { (USA) } \\ & \text { E-Mail eyesitemd@gmail.com }\end{aligned}$




\section{Case Reports in Ophthalmology}

Saffra and Reinherz: Peripapillary Choroidal Neovascularization Associated with Optic Nerve Head Drusen Treated with Anti-VEGF Agents

factor (anti-VEGF) agent. A change of medication was required in order to achieve a therapeutic response.

\section{Case}

A 75-year-old male presented with a chief complaint of blurry vision in the right eye (OD) of 3 months duration. The patient's past medical and ocular history were significant only for herpes zoster ophthalmicus on the left side years prior. On examination, the bestcorrected visual acuity (BCVA) was 20/60 OD. An anterior segment examination was unremarkable. The fundus examination revealed peripapillary CNV (fig. 1) with fluid tracking toward the macula. B-scan ultrasonography and autofluorescent photography confirmed the presence of ONHD (fig. 1). Fluorescein angiography revealed peripapillary CNV with macular extension. Ocular coherence tomography (OCT) demonstrated subfoveal fluid (fig. 2). His treatment was initiated with 3 ranibizumab injections, administered every 5 weeks, without any impact on the amount of subfoveal fluid. Subsequent treatment with a single aflibercept injection resulted in complete resolution of subfoveal fluid (fig. 2) and an improvement of the patient's BCVA to 20/30 OD. Two additional maintenance aflibercept injections were given during the next 3 months (fig. 2). The patient's visual acuity has been stable for 15 months with no recurrence of subfoveal fluid.

\section{Discussion}

The association of ONHD with macular threatening PPCNVM and its favorable response to anti-VEGF agents is already known in the pediatric population [2-4]. The natural course of PPCNVM is variable and unpredictable; however, macular threatening PPCNVM requires treatment [2]. While the role of anti-VEGF therapy as a treatment for this specific subset of choroidal neovascular membranes was not studied as part of the major neovascular agerelated macular degeneration (AMD) studies [5], its use for the treatment of other forms of $\mathrm{CNV}$ is well established [6].

Bevacizumab, ranibizumab and aflibercept are 3 anti-VEGF agents used for the treatment of neovascular AMD. Ranibizumab and bevacizumab are monoclonal antibodies that selectively bind to VEGFA [7, 8]. Aflibercept, however, is a fusion protein composed of the binding domains of VEGF receptor 1 , VEGF receptor 2, and the Fc portion of IgG that selectively binds to VEGFA, VEGFB, and platelet growth factor (PIGF) [9]. Aflibercept has been shown to have a greater affinity for VEGF and a longer half-life than both ranibizumab and bevacizumab [10].

The Comparison of Age-Related Macular Degeneration Treatment Trials (CATT) [5] demonstrated equivalence in efficacy between ranibizumab and bevacizumab in the treatment of wet AMD, as did the Inhibition of VEGF in the Age-Related Choroidal Neovascularization (IVAN) trial [11]. The VEGF Trap-Eye: Investigation of Efficacy and Safety in Wet AMD (VIEW 1 and VIEW 2) trials [12] similarly demonstrated an equivalence between ranibizumab and aflibercept in treating wet AMD. Inadequate response to 1 anti-VEGF agent is not uncommon when treating CNV [1], and, on occasion, changing to an alternate anti-VEGF agent has demonstrated efficacy [1]. Currently, there are no studies that have investigated the response of aflibercept in treatment-resistant peripapillary CNV, likely due to the rarity of this presentation. Previous studies have concluded that aflibercept may provide an efficacious therapeutic response in cases of CNV due to AMD that initially failed to respond to 
Saffra and Reinherz: Peripapillary Choroidal Neovascularization Associated with Optic Nerve Head Drusen Treated with Anti-VEGF Agents

bevacizumab and ranibizumab [1]. Further studies are required to investigate whether aflibercept is an equally efficacious therapeutic alternative to treatment resistant peripapillary CNV. Based upon our experience, an individualized treatment plan for adult patients with PPCNVM, associated with ONHD, may be required.

\section{Disclosure Statement}

The authors have no financial or proprietary interests to disclose.

\section{References}

$\checkmark 1$ Chang AA, Li H, Broadhead GK, Hong T, et al: Intravitreal aflibercept for treatment-resistant neovascular age-related macular degeneration. Ophthalmology 2014;121:188-192.

-2 Jutley G, Jutley G, Tah V, Lindfield D, Menon G: Treating peripapillary choroidal neovascular membranes: a review of the evidence. Eye 2011;25:675-681.

-3 Davis AS, Folk JC, Russell SR, et al: Intravitreal bevacizumab for peripapillary choroidal neovascular membranes. Arch Ophthalmol 2012;130:1073-1075.

4 Delas B, Almudí L, Carreras A, Asaad M: Bilateral choroidal neovascularization associated with optic nerve head drusen treated by antivascular endothelial growth factor therapy. Clin Ophthalmol 2012;6:225-230.

-5 Comparison of Age-related Macular Degeneration Treatments Trials (CATT) Research Group; Martin DF, Maguire MG, Fine SL, et al: Ranibizumab and bevacizumab for neovascular age-related macular degeneration: two year results. Ophthalmology 2012;119:1388-1398.

-6 Salehipour M, Vafi N, Doozande A, Yaseri M: Intravitreal bevacizumab for choroidal neovascularization secondary to non-age-related macular degeneration. J Ophthalmic Vis Res 2010;5:10-19.

-7 Rich RM, Rosenfeld PJ, Puliafito CA, et al: Short-term safety and efficacy of intravitreal bevacizumab (avastin) for neovascular age related macular degeneration. Retina 2012;26:495-511.

-8 Rosenfeld PJ, Brown DM, Heier JS, et al: Ranibizumab for neovascular age-related macular degeneration. N Engl J Med 2006;355:1419-1431.

-9 Browning DJ, Kaiser PK, Rosenfeld PJ, Stewart MW: Aflibercept for age-related macular degeneration: a game-changer or quiet addition? Am J Ophthalmol 2012;154:222-226.

10 Stewart MW, Rosnfeld PJ, Penha FM, et al: Pharmacokinetic rationale for dosing every 2 weeks versus 4 weeks with intravitreal ranibizumab, bevacizumab, and aflibercept (vascular endothelial growth factor Trap-eye). Retina 2012;32:434-457.

11 IVAN Study Investigators; Chakravarthy U, Harding SP, Rogers CA, et al: Ranibizumab versus bevacizumab to treat neovascular age-related macular degeneration: one-year findings from the IVAN randomized trial. Ophthalmology 2012;119:1399-1411.

$\longrightarrow 12$ Heier JS, Brown DM, Chong V, et al: Intravitreal aflibercept (VEGF trap-eye) in wet age-related macular degeneration. Ophthalmology 2012;119:2537-2548. 


\section{Case Reports in \\ Ophthalmology}

Case Rep Ophthalmol 2015;6:51-55

DOI: $10.1159 / 000375480$

2015 S. Karger AG, Basel

www.karger.com/cop

Saffra and Reinherz: Peripapillary Choroidal Neovascularization Associated with Optic Nerve Head Drusen Treated with Anti-VEGF Agents

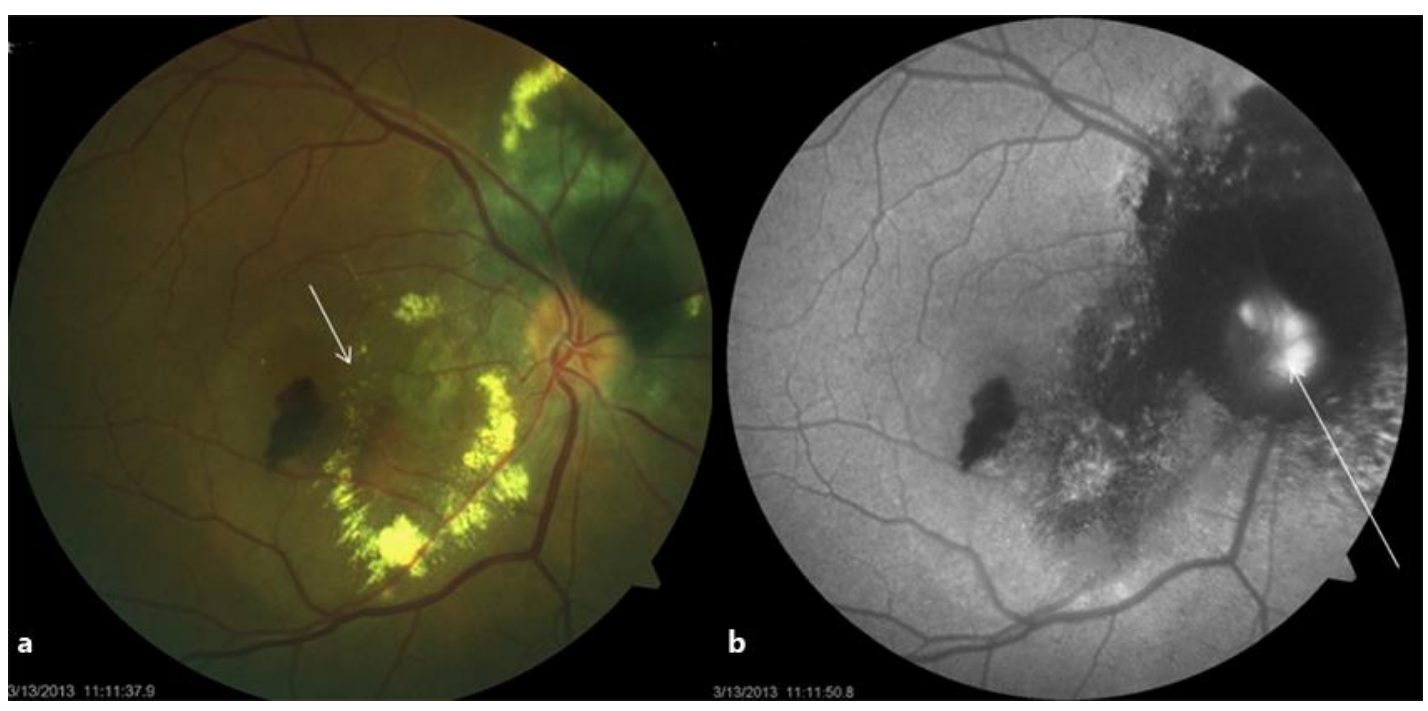

Fig. 1. a Color fundus photograph OD demonstrating a nasal peripapillary neovascular membrane with an extension of blood and fluid into the fovea (short arrow). b The corresponding autofluorescent photograph depicts ONHD (long arrow). 


\section{Case Reports in \\ Ophthalmology}

Case Rep Ophthalmol 2015;6:51-55

DOI: $10.1159 / 000375480$

2015 S. Karger AG, Basel

www.karger.com/cop

Saffra and Reinherz: Peripapillary Choroidal Neovascularization Associated with Optic Nerve Head Drusen Treated with Anti-VEGF Agents

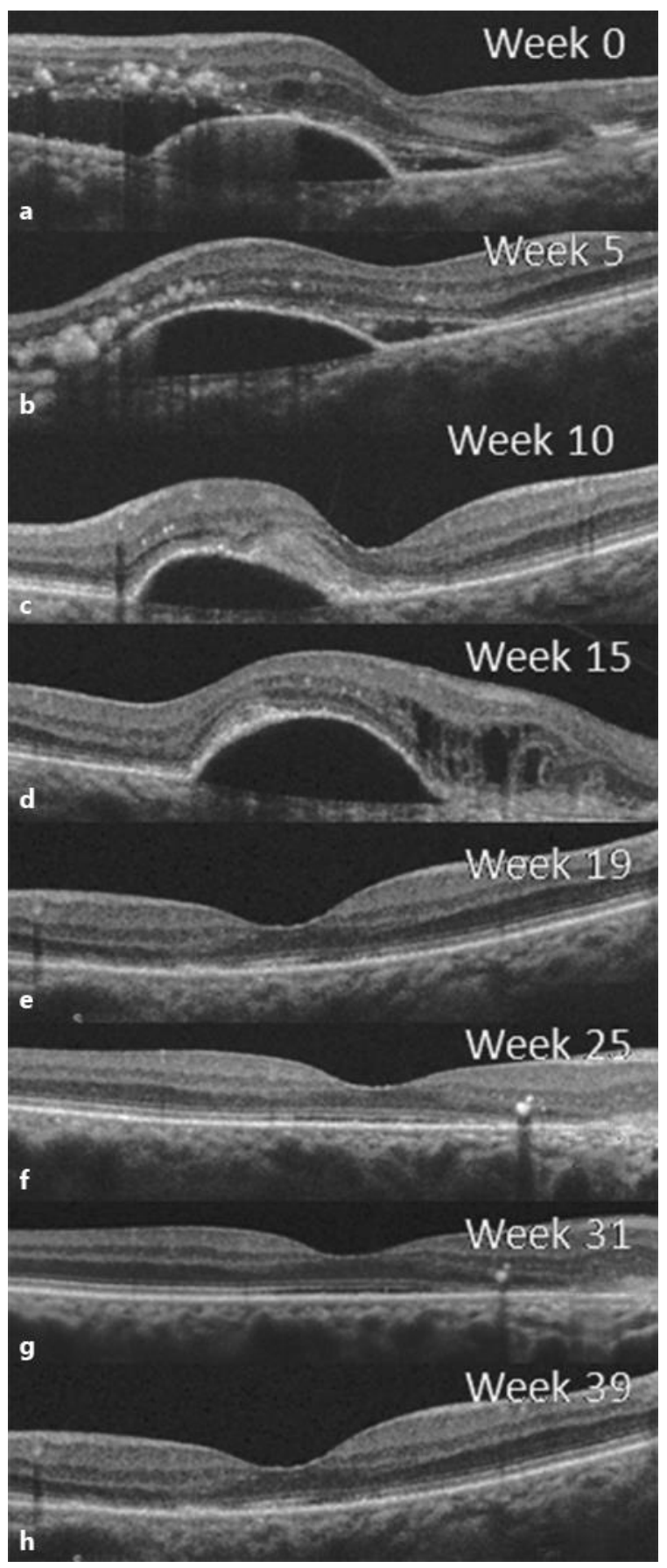

Fig. 2. Macular OCT demonstrating subfoveal fluid and pigment epithelial detachment at initial presentation (a) and subsequent response to ranibizumab (b-d) and aflibercept injections (e-h). Ranibizumab injections were administered at weeks 0,5 , and 10 . Aflibercept injections were administered at weeks 15 , 25 , and 31. OCT images are labeled with corresponding dates. 